\title{
Motor Fault Detection Using a Rogowski Sensor Without an Integrator
}

\author{
Oscar Poncelas, Javier A. Rosero, Jordi Cusidó, Member, IEEE, \\ Juan Antonio Ortega, Member, IEEE, and Luis Romeral, Member, IEEE
}

\begin{abstract}
This paper presents a new approach for the current acquisition system in motor fault detection applications. This paper includes the study, design, and implementation of a Rogowskicoil current sensor without the integrator circuit that is typically used. The circuit includes an autotuning block able to adjust to different motor speeds. Equalizing the amplitudes of the fundamental and fault harmonics leads to higher precision current measurements. The resulting compact sensor is used as a current probe for fault detection in induction motors through motor current signal analysis. The use of a Rogowski coil without an integrator allows a better discrimination of the fault harmonics around the third and fifth main harmonics. Finally, the adaptive conditioning circuit is tested over an induction machine drive. Results are presented, and quantitative comparisons are carried out.
\end{abstract}

Index Terms-Current sensor, motor current signal analysis (MCSA), motor drive, Rogowski.

\section{INTRODUCTION}

$\mathbf{E}$ LECTRICAL motors are the most common way to convert electrical power to mechanical power in the industry. Among them, induction motor (IM) and permanent magnet (PM) motor are the most widely used. Of the industrial applications, 70\% use induction machines, but PM ac machines are increasingly used due to their high performance. Many industrial applications require high reliability and availability, which have become the major concerns in processes such as aeronautics, robotics, machine positioning, and automobiles, among others. Efficient condition monitoring and accurate machine fault diagnosis are, thus, desirable in order to reduce the impact of damage and to improve operational efficiency.

Motor faults can be classified as electrical and mechanical faults [1], [2]. Among these: 1) bearing; 2) stator or armature faults; 3 ) eccentricity-related faults; and 4) broken rotor bar and end ring faults of induction machines are the most prevalent ones and, thus, demand special attention.

Quantification of faults is as follows: $41 \%$ bearings, $37 \%$ stator faults, $12 \%$ eccentricities, and $10 \%$ broken rotor bars.

Manuscript received October 31, 2008; revised June 12, 2009. First published June 26, 2009; current version published September 16, 2009. This work was supported in part by the Spanish Ministry of Education and Science under the DPI2007-66688-C02-01 Research Project.

The authors are with the Motion Control and Industrial Applications Group, Department of Electronic Engineering, Universitat Politècnica de Catalunya, 08222 Terrassa, Spain (e-mail: oscar.poncelas@upc.edu; jcusido@eel.upc.edu; jaortega@eel.upc.edu; romeral@eel.upc.edu;).

Color versions of one or more of the figures in this paper are available online at http://ieeexplore.iee.org.

Digital Object Identifier 10.1109/TIE.2009.2025715
Significant efforts have been invested in the diagnosis of motor faults during the last decades, and many techniques have been proposed [3]-[19]. Several of these fault detection and identification techniques are based on physical phenomena like vibration monitoring [4], electromagnetic field monitoring by means of search coils [5], electrical measurements [6], machine models [7], or even a combination of different diagnostic methods, such as mechanical, chemical, and thermal [8].

Although manufacturers and users of electrical machines initially relied on simple protection against overcurrent, overvoltage, and earth faults to ensure safe and reliable operation, nowadays, the tasks performed by these machines have become increasingly complex, and improvements have also been sought in the field of fault diagnosis. Recently, new techniques based on artificial intelligence approaches have been introduced [9], which use concepts such as fuzzy logic [10], [11], genetic algorithms [12], and neural networks [13]-[15] to detect, identify, and diagnose the state of the motor.

Among the different motor fault detection methods, the spectral signature analysis of the stator current known as motor current signal analysis (MCSA) is currently considered to be the most popular fault detection method for online diagnosis [16]. The basis of the MCSA is that the stator current contains current components directly linked to rotating flux components caused by electrical or mechanical faults. These harmonic current components caused by faults can be used for early failure detection.

Condition monitoring based on stator currents is advantageous due to its easy and cost-effective implementation. It is nonintrusive and uses the stator winding as the search coil, and it is not affected by the type of load and other asymmetries. The monitoring is usually done in a steady operation state using classical fast Fourier transform (FFT). However, many drives are adjustable speed drives, where mechanical speed transients may be present during a long period of time. The resulting time-varying supply frequency prevents the use of classical spectral analysis, and other signal processing methods such as time-frequency analysis must be used [17]-[19].

All of these techniques share the need for data acquisition. To perform the MCSA, stator currents are measured by current meters, digitalized, and stored by time domain. The time domain is not suitable for the representation of current signals; thus, frequency or time-frequency domains are applied to the analysis of signals. After signal decomposition, signal features must be extracted and entered into a pattern classification model, which performs diagnosis and prognosis to detect a failure in advance. 
Different current sensing methods can be used to obtain a signal equivalent to the current. Among them, shunt techniques, Hall effect sensors, and current transformers are the most frequently used.

Another possible sensor used to measure the current is the Rogowski coil, which was first introduced in 1912 to measure magnetic fields. Lately, Rogowski coils have been proposed to measure acs [20]-[22] and for fault detection [23].

A Rogowski coil, named after its inventor, is a uniformly wound coil on a nonmagnetic former of constant cross-sectional area formed in a closed loop. The coil surrounds the primary current to produce a voltage that is proportional to the time derivative of the primary current and the mutual inductance of the coil. The coil output is then integrated by an integrator to recover the primary current signal. It can be used to measure acs of tens of amperes or greater through the principles described by Faraday's law.

Signals from the transducer have a high signal-to-noise ratio at these values, allowing the use of simple amplification and filtering techniques and resulting in ac measurement systems with better linearity, versatility, and cost compared to conventional instruments. Moreover, Rogowski coils do not have ferromagnetic material in their cores, which means that the coils will never be saturated. Other advantages of Rogowski transducers include the following: nonintrusiveness, full isolation, good linearity, high bandwidth, ease of use (can be thin and flexible), no consequences from dc saturation effects, and relative simplicity and inexpensiveness to manufacture.

When a Rogowski coil is placed around a current-carrying conductor, according to Faraday's law, the output signal is proportional to the time derivative of the measured current.

To obtain a signal that is proportional to the monitored current, the output signal of the coil must be integrated. This is the reason why it is necessary to use an integrator circuit to obtain the stator current with the traditional Rogowski current transducer [24]. This is a disadvantage when measurements are carried out in an inverter drive. Due to modulation, the inverter can introduce a dc component on common mode that causes saturation in the integrator circuit. Also, in the case of active analog integration, the integrator adds a dc offset component that generates a ramp which will ultimately increase to be a significant error in the output signal, demanding either the use of a high-pass filter that needs to be well tuned in order not to alter signal data [25] or an additional circuit to reset the integrator to zero when the current through the Rogowski coil is equal to zero [26], which complicates the sensor and makes it more expensive.

This paper presents the study, design, and implementation of a Rogowski-coil current sensor as a sensor for MCSA fault detection without the integration block that is typically used. Instead of using analog or digital integration, the sensor directly provides the derivative of the measured current. In this way, the current acquisition system can take advantage of the inherent Rogowski coil characteristic: amplification of the current harmonics by a frequency.

By using a bandpass filter to diminish main harmonic and cutoff switching high frequencies, the acquisition system can be tuned to the frequency range that contains the more interesting fault harmonics. This compact sensor can be used as a current probe for MCSA fault detection in electrical motors. This paper is an extended version of another one presented at the 2008 IEEE International Symposium on Industrial Electronics [27]. It has been enhanced with the following elements.

1) The introduction has been updated with the most recent journal references.

2) A theoretical background of fault currents has been included.

3) Adaptive electronics have been developed to tune the sensor operation to the motor speed.

4) Experimental results are now clearer and more accurate.

5) Conclusions of this paper have been reviewed and improved.

Following this introduction, Section II presents the sensor block details and sensor characterization. Section III deals with the experimental results obtained from the faults staged on the IM tested by measuring the currents with the proposed sensor. Finally, in Section IV, the summary and conclusions drawn from this study are presented.

\section{Motor Current ACQuisition System}

As stated in Section I, MCSA is considered as the most promising noninvasive fault detection method, as it allows the detection of several common machine faults through simple measurements and the processing of the stator current under normal operation of the machine.

Generally speaking, three-phase currents under fault conditions can be expressed as follows:

$$
\begin{aligned}
i_{R}(t)= & \sqrt{2} I_{R} \sin 2 \pi f_{1} t+\sqrt{2} \sum_{n=0}^{N} I_{R n} \sin \left(2 \pi f_{n} t-\varphi_{R n}\right) \\
i_{S}(t)= & \sqrt{2} I_{S} \sin \left(2 \pi f_{1} t-2 \pi / 3\right) \\
& +\sqrt{2} \sum_{n=0}^{N} I_{S n} \sin \left(2 \pi f_{n} t-\varphi_{S n}-2 \pi / 3\right) \\
i_{T}(t)= & \sqrt{2} I_{T} \sin \left(2 \pi f_{1} t-4 \pi / 3\right) \\
& +\sqrt{2} \sum_{n=0}^{N} I_{T n} \sin \left(2 \pi f_{n} t-\varphi_{T n}-4 \pi / 3\right)
\end{aligned}
$$

where $I_{R}=I_{S}=I_{T}=I$ are the rms values of the fundamental component of the line current; $I_{R n}, I_{S n}$, and $I_{T n}$ are the rms values of the fault components; and $\varphi_{R n}, \varphi_{S n}$, and $\varphi_{T n}$ are the angular displacements of the fault components.

The space vector $\vec{i}_{s}$ referring to the stator reference frame is obtained by applying the transformation of the symmetrical components

$$
\begin{aligned}
\overrightarrow{i_{s}}= & \sqrt{\frac{2}{3}}\left[i_{R}+i_{S} e^{j 2 \pi / 3}+i_{T} e^{-j 2 \pi / 3}\right] \\
=\sqrt{3}\left[I e^{j 2 \pi f_{s} t}+I_{1} e^{j\left[2 \pi f_{1} t-\varphi_{1}\right]}\right. & \\
& \left.\quad+I_{2} e^{j\left[2 \pi f_{2} t-\varphi_{2}\right]}+\cdots+I_{n} e^{j\left[2 \pi f_{n} t-\varphi_{n}\right]}\right] .
\end{aligned}
$$

Fault frequencies $f_{1}, \ldots, n$ are related to different faults in the induction machine [2], such as air-gap eccentricity (3), 
shorted turns (4), and broken rotor bars

$$
\begin{gathered}
f_{e c c}=f_{1}\left[1 \pm m\left(\frac{1-s}{p}\right)\right] \\
f_{s t}=f_{1}\left[\frac{m}{p}(1-s) \pm k\right] \\
f_{b r b}=f_{1}\left[m\left(\frac{1-s}{p}\right) \pm s\right]
\end{gathered}
$$

where $m$ is the harmonic order, $f_{1}$ is the main frequency, $s$ is the slip, $p$ is the number of paired poles, and $k=0,1,3,5 \ldots$. Fault harmonic position is directly dependent on the slip value, and slip is directly dependent on the motor load. Higher load produces higher slip, and, hence, a fault harmonic could be easier distinguished.

Shorted turns could also be detected, analyzing additional harmonics at the medium band of the spectra [28], which depend on the number of rotor slots $Z_{2}$

$$
f_{\text {sth }}=f_{1}\left[1 \pm m Z_{2}\left(\frac{1-s}{p}\right)\right] \text {. }
$$

As stated, abnormal harmonics $f_{n}$, which appear in a stator current, are functions of a number of variables due to the magnetomotiveforce distribution and the permeance-wave representation of the air gap. In a variable speed drive, a current control algorithm may exist that tries to provide symmetric stator currents through the application of asymmetrical stator voltages in order to reach this goal in spite of the fault's abnormal harmonics. Therefore, it is important to assure that the abnormal harmonic frequencies considered in fault detection are beyond the cutoff frequency of the drive's control transfer function.

The stator current of the IM machine under fault conditions is a combination of different frequency components as it can be seen in (2). If this current is measured with the proposed Rogowski sensor, without the integrator, (2) will take the following form:

$$
\begin{aligned}
\frac{d i_{R}(t)}{d t}= & 2 \pi f_{1} \sqrt{2} I_{R} \cos 2 \pi f_{1} t \\
& +\sqrt{2} \sum_{n=0}^{N}\left[2 \pi f_{n} I_{R n} \cos \left(2 \pi f_{n} t-\varphi_{R n}\right)\right] \\
\frac{d i_{S}(t)}{d t}= & 2 \pi f_{1} \sqrt{2} I_{S} \cos \left(2 \pi f_{1} t-2 \pi / 3\right) \\
& +\sqrt{2} \sum_{n=0}^{N}\left[2 \pi f_{n} I_{S n} \cos \left(2 \pi f_{n} t-\varphi_{S n}-2 \pi / 3\right)\right] \\
\frac{d i_{T}(t)}{d t}= & 2 \pi f_{1} \sqrt{2} I_{T} \cos \left(2 \pi f_{1} t-4 \pi / 3\right) \\
& +\sqrt{2} \sum_{n=0}^{N}\left[2 \pi f_{n} I_{T n} \cos \left(2 \pi f_{n} t-\varphi_{T n}-4 \pi / 3\right)\right] .
\end{aligned}
$$

The derivative operator is linear, i.e., it changes the modules and phases of the sine components, but it does not create new frequencies.

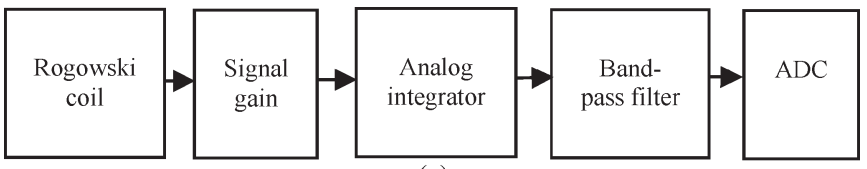

(a)

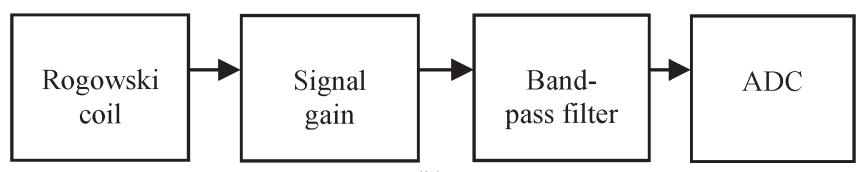

(b)

Fig. 1. (a) Block diagram of the traditional acquisition system. (b) Block diagram of the proposed acquisition system.

For the purpose of fault detection with MCSA, we have considered the spectral analysis of the stator current, and the phase has not been relevant. The difference with the traditional transducer is that, with the proposed Rogowski sensor, the frequency harmonics increase their amplitude since they are scaled by their respective $\omega(2 \pi f)$. This helps the harmonic in the presence of noise, particularly at high frequencies.

It must be noted that fault detection is usually better performed at high frequencies, either by analyzing the spectra around the main harmonics or by injecting high-frequency voltage test frequencies or by reading the corresponding current harmonics [29], [30]. In conclusion, a Rogowski coil without an integrator enhances high current frequencies, which aids fault detection through MCSA.

The traditional block diagram for current measurement with a Rogowski coil is shown in Fig. 1(a). This paper's proposal uses a Rogowski coil without the integrator circuit [Fig. 1(b)].

\section{A. Rogowski Without Integrator Transducer}

As we have seen before, the use of an integrator is problematic since it is difficult to adjust and it shows a tendency to saturation. The power supply of the induction machine usually comes from a power inverter. This type of power source generates high-frequency signals that may be nonsymmetrical, i.e., signals have different negative and positive parts, and the nonzero average can saturate the integrator circuit.

At the output of the Rogowski coil, we obtain an output signal that is proportional to current changes

$$
V_{o}=\frac{\mu_{0} n A}{2 \pi r} \frac{d i}{d t}=M \frac{d i}{d t}
$$

where $\mu_{0}=4 \pi \times 10^{-7} \mathrm{H} / \mathrm{m}$ is the permeability of free space, $n$ is the number of turns, $A$ is the cross-sectional area in square meters, and $r$ is the radius of the coil in meters. The constant term $M$ represents the mutual inductance of the Rogowski coil.

The output voltage of the coil must be integrated to provide the current. For our purpose, the Rogowski coil is designed with the shape of a polyethylene toroid core with $n=500$, $A=64 \mathrm{~mm}^{2}$, and $r=10 \mathrm{~mm}$. With these values, the mutual inductance is about $M=640 \mathrm{nH}$. Axial return wire design is used, and gaps and overlaps in the winding have been minimized to reduce sensitivity to external disturbances. The signal 

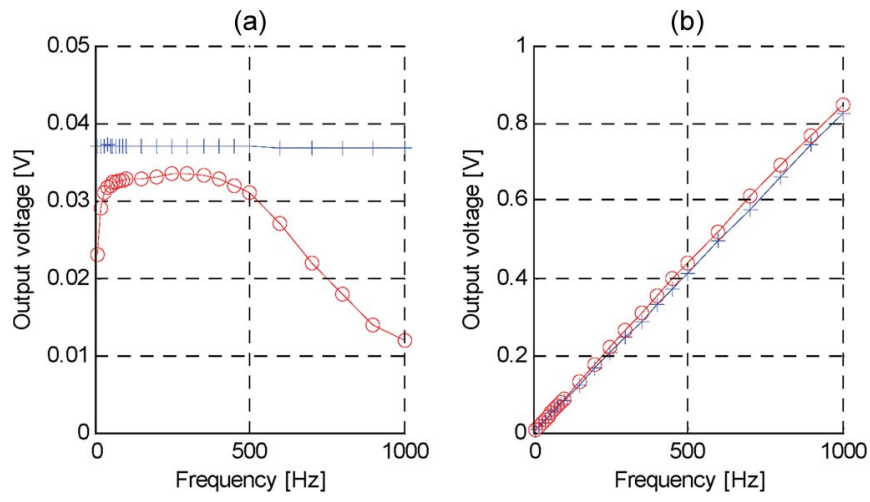

Fig. 2. Sensor output. (a) Output voltage of $(+)$ a commercial transducer and (o) a traditional Rogowski-coil transducer. (b) Output voltage of the Rogowskicoil transducer without an integrator, $(+)$ theoretical and $(\mathrm{o})$ measured.

gain block is a noninverting amplifier with a gain of $60 \mathrm{~dB}$. The bandpass filter block is discussed in detail in Section II-B.

The bandpass filter block is discussed in detail in Section II-B, and the analog-to-digital converter (ADC) block is a standard microprocessor-based signal acquisition with 12-b resolutions, with a sample frequency of $f_{s}=10000 \mathrm{~Hz}$.

Several tests have been performed to evaluate the operation of the transducer. The value of $M$ has been obtained by measuring $Z$ parameters with a Rohde \& Schwarz ZVRE network analyzer. A value of $669.4 \mathrm{nH}$ is obtained. The whole current transducer proposed has been tested with a conductor carrying a current of 0.2 A obtained through a function generator instrument. The output of the Rogowski transducer without an integrator has been compared with the outputs of a commercial transducer and a traditional Rogowski transducer.

The commercial transducer is the Tektronix A622 that uses a Hall effect current sensor to provide a voltage output. It can measure acs/dcs from $50 \mathrm{~mA}$ to $100 \mathrm{~A}$ peak over a frequency range of dc to $100 \mathrm{kHz}$.

The traditional Rogowski transducer was manufactured using the same coil as the Rogowski transducer without an integrator. It is designed to measure currents up to $10 \mathrm{~A}_{\text {rms }}$ over a frequency range from 10 up to $500 \mathrm{~Hz}$.

Fig. 2(a) shows the output voltage of the commercial transducer and the traditional Rogowski coil with an integrator. We can see that, at frequencies higher than $500 \mathrm{~Hz}$, the traditional Rogowski coil acts as a low-pass filter. This is done by the integrator circuit.

Fig. 2(b) shows the output of the Rogowski coil without an integrator, with its theoretical and experimental results. One can see how the harmonics increase its amplitude with the frequency.

Another test to validate the transducer is to put a conductor carrying a square current through the coil. At the output of the transducer, all the harmonics must have the same amplitude. The harmonic decomposition of the square signal is

$$
i(t)=\frac{4 V}{\pi} \sum_{n=1}^{\infty}\left(\frac{1}{n} \sin \left(n \cdot \omega_{o} t\right)\right)
$$

where $V$ is the amplitude of the square signal, $\omega_{0}$ is the fundamental frequency, and $n$ are the odd numbers.
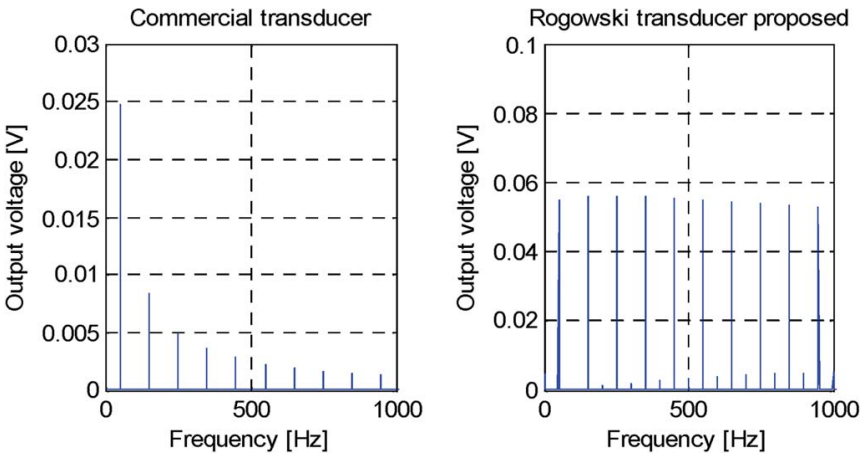

Fig. 3. Current spectrum of a square signal measured with a commercial transducer and with the proposed Rogowski transducer.

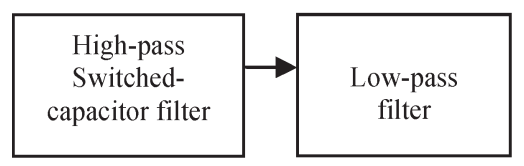

Fig. 4. Block diagram of the bandpass filter.

The harmonic decomposition at the output of the Rogowski transducer is

$$
y(t)=M \frac{d i}{d t}=M \frac{4 V}{\pi} \sum_{n=1}^{\infty}\left(\omega_{o} \cos \left(n \cdot \omega_{o} t\right)\right) .
$$

This should be corroborated by the results obtained in Fig. 3. To the left, we can see the output of a commercial current transducer, and, to the right, we can see the output of the suggested Rogowski transducer.

Using the proposed Rogowski transducer is a good solution to monitor the harmonics at frequencies above the main harmonic since the harmonics take more amplitude regarding the main harmonic.

A combination of the reduced main harmonic (due to the filter) and the amplified fault harmonics (due to lack of integration) will produce a similar amplitude for all harmonics passing the filter and, thus, better use of the acquisition system dynamic range.

\section{B. Proposed Acquisition Circuit for Variable Operating Conditions}

When we consider variable conditions, the bandpass filter block is comprised by the blocks in Fig. 4. The main part is an adaptive filter using a switched-capacitor filter.

The idea is to measure the first harmonic as well as the harmonics that appear due to the fault near the fifth harmonic. The magnitude of the fault harmonics near the fifth harmonic with respect to the fundamental harmonics is about $40 \mathrm{~dB}$ below.

The proposed method is based on the attenuation of the fundamental harmonic and the amplification of the band of the fault harmonics, obtaining a theoretically similar amplitude for the fundamental and the fifth harmonics.

In this paper, we want to measure the fault harmonics due to broken rotor bar faults and eccentricity faults. In order to detect broken bar faults, the classical method of analysis 


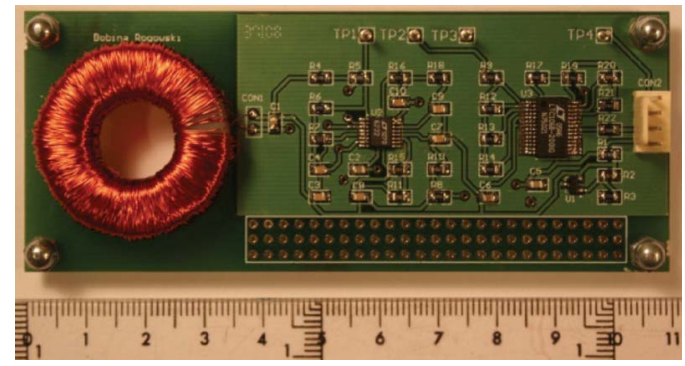

Fig. 5. Proposed Rogowski sensor with the adaptive filter.

through MCSA uses the first harmonic, observing the fault near $f_{1}(1 \pm 2 s)$. Other studies propose evaluating the side of the fifth harmonic, finding the fault near $f_{1}(5-4 s)$ and $f_{1}(5-6 s)$.

To detect eccentricities, any harmonic given by the expression can be evaluated (3). In this paper, we have considered the side of the third harmonic.

The high-pass switched-capacitor filter selects the analyzed frequency band. Additionally, this filter equalizes the amplitude of the main harmonic which, then, has similar amplitude to the fifth harmonic. With these requirements, the cutoff frequency of the switched-capacitor filter is $2 f_{1}$ ( $f_{1}$ is the fundamental frequency of the stator current). This cutoff frequency is adjusted externally by a clock signal. With a fourth-order filter and $2 f_{1}$ cutoff frequency, the attenuation at $f_{1}$ is always one octave. Resolution of the proposed sensor is enough to detect the fault harmonics with the amplitude lower than the threshold arbitrarily established in $40 \mathrm{~dB}$ below the main harmonic.

As we can see in Fig. 4, the main part of the adaptive system is the switched-capacitor filter. This is comprised by two second-order parts based on the LTC1068 component of Linear Technology, comprising a fourth-order high-pass filter.

An $R C$ network is used to avoid aliasing in the switchedcapacitor filter. Before ADC, a low-pass filter is used to avoid aliasing in the digital acquisition system. The cutoff frequency of an antialiasing filter is $400 \mathrm{~Hz}$.

Fig. 5 shows a picture of the developed Rogowski sensor. With the method that has been proposed, the MCSA is performed by comparing the fundamental frequency to the fault harmonics and observing the time evolution. Fig. 6 depicts the frequency response of the bandpass filter for two different working points.

\section{EXPERIMENTAL RESULTS}

\section{A. Test Bench}

To check the transducer for fault detection in an IM, several tests have been done with a three-phase 1.1-kW 400/230-V 50-Hz 1410-r/min four-pole IM.

First, the behavior of the healthy motor was studied, and, after motors with eight rotor bars, damaged and eccentricity faults were analyzed. The motor nameplate is shown in Table I. The motor under test is controlled with a voltage-frequency control implemented in a TMS320F2812 digital signal processor manufactured by Texas Instruments.

The current has been measured by two transducers: a traditional Rogowski sensor with the integrator hardware and
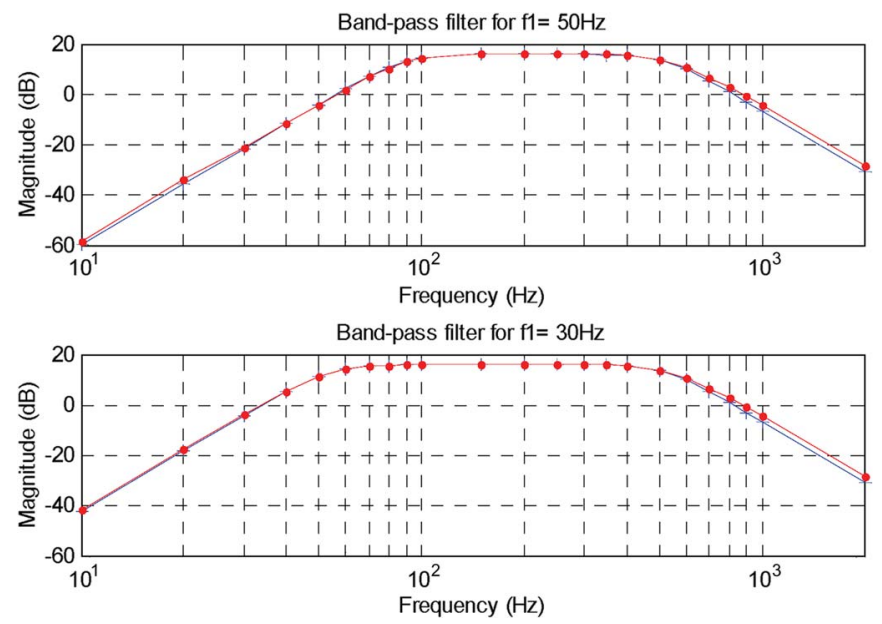

Fig. 6. Frequency response of the bandpass filter for a main stator current harmonic of 50 and $33 \mathrm{~Hz},(+)$ theoretical and (o) measured.

TABLE I

SPECIFICATIONS OF IM-TyPE MOdEL

\begin{tabular}{|c|c|}
\hline Induction Motor & Value \\
\hline Rated power & $1.1 \mathrm{~kW}$. Star: $380 \mathrm{~V} / 2.6 \mathrm{~A}$ \\
\hline Number of poles & 4 \\
\hline Nominal speed & $1410 \mathrm{rev} / \mathrm{min}$ \\
\hline Cos $\varphi$ & 0.81 \\
\hline
\end{tabular}

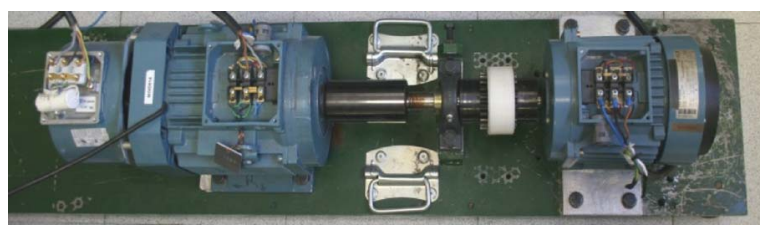

Fig. 7. IM test bench for fault detection.

the Rogowski transducer proposed in this paper (Fig. 6). The traditional Rogowski sensor measures the currents up to $20 \mathrm{~A}$, from 10 to $500 \mathrm{~Hz}$, and with a sensibility of $148 \mathrm{mV} / \mathrm{A}$.

The fully analyzed band ranges from 0 to $400 \mathrm{~Hz}$ with a resolution of $0.2 \mathrm{~Hz}$ for FFT analysis, which is enough to cover the significant band of an induction machine and to distinguish the harmonics due to a fault.

The test rig and the data are shown in Fig. 7. Load control has been implemented by using an IM and a commercial inverter, where variable load order was introduced.

\section{B. Fourier Analysis of Motor Stator Currents for Different Operating Conditions}

Fig. 8 illustrates the stator current spectrum of a healthy motor measured with a traditional Rogowski coil and with the proposed Rogowski sensor.

We can observe how the fundamental harmonic takes similar amplitude to the third and fifth harmonics if the current is measured with the proposed Rogowski sensor. If we compare the two graphs, we can see that the harmonics of high frequencies are higher with the proposed Rogowski sensor than with the traditional Rogowski sensor. 
Traditional Rogowski sensor

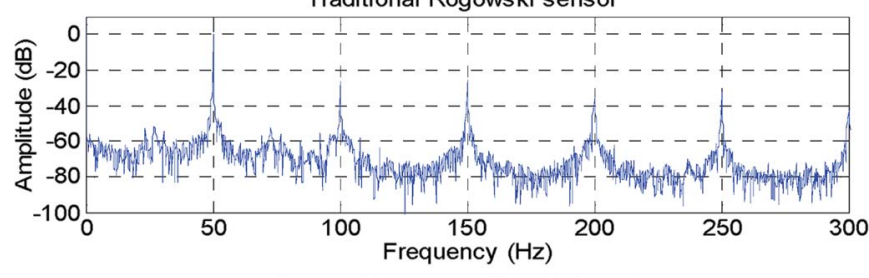

Rogowski sensor without integrator

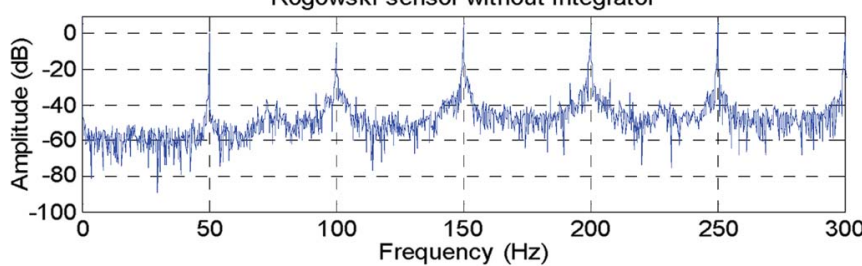

Fig. 8. Stator current spectrum of a healthy IM supplied with $50 \mathrm{~Hz}$. (a) Traditional Rogowski sensor. (b) Rogowski sensor without an integrator.
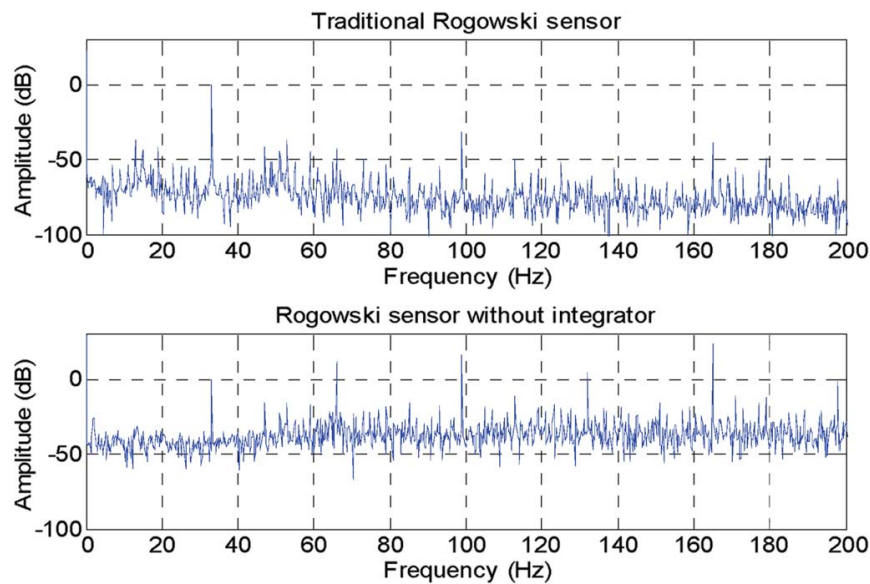

Fig. 9. Stator current spectrum of a healthy IM supplied with $33 \mathrm{~Hz}$.

Fig. 9 depicts the current spectrum of the same motor supplied with a different current frequency. The adaptive filter changes the cutoff frequency to a new one adapted to the new conditions. Again, it is easy to see that the harmonics with high frequencies take more amplitude if they are measured with the proposed Rogowski sensor. Fig. 10 shows the detail near the fifth harmonic of the current spectrum of an IM with eight broken bars (right side) as opposed to the current spectrum of a healthy motor (left side). Both motors have been supplied with $50 \mathrm{~Hz}$. All the graphs are normalized to $0 \mathrm{~dB}$ at the peak of the fundamental frequency.

Harmonics that appear due to the fault are inside the ovals. In the graphs, we can appreciate how these harmonics concerning the main harmonic increase their amplitude if they are measured with the proposed Rogowski sensor.

The amplitude of these harmonics measured with the proposed transducer is more than $25 \mathrm{~dB}$ higher than the harmonics obtained with the traditional Rogowski sensor. This means that the fault can easily be detected and that it is possible to use an $\mathrm{ADC}$ with less resolution in the acquisition hardware.

Fig. 11 shows the same motor supplied with $33 \mathrm{~Hz}$. The fault harmonics are inside an oval again. In this situation, the fault harmonics measured with the proposed Rogowski sensor are (a)

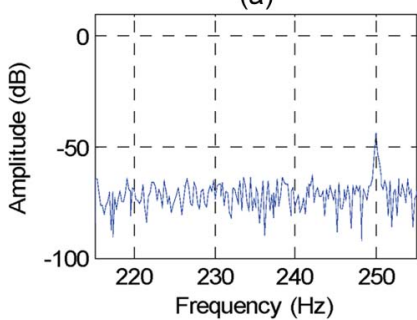

(b)

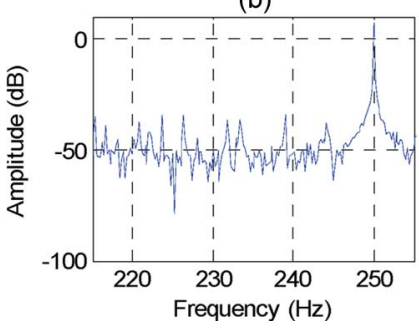

(c)

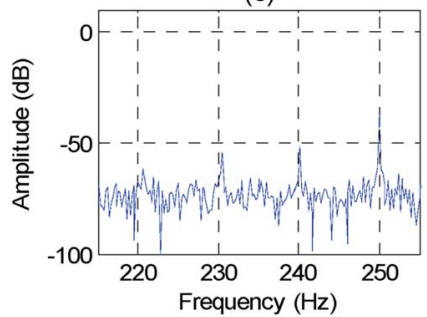

(d)

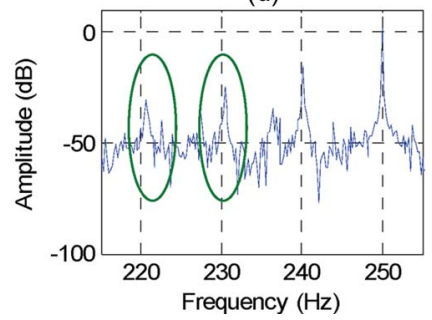

Fig. 10. Stator current spectrum of an IM supplied with $50 \mathrm{~Hz}$. Fifth harmonic sideband. (a) Healthy motor measured with a traditional Rogowski sensor. (b) Healthy motor measured with a Rogowski sensor without an integrator. (c) Motor with broken bars measured with a traditional Rogowski sensor. (d) Motor with broken bars measured with a Rogowski sensor without an integrator.

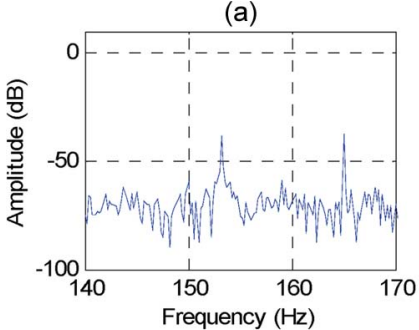

(b)
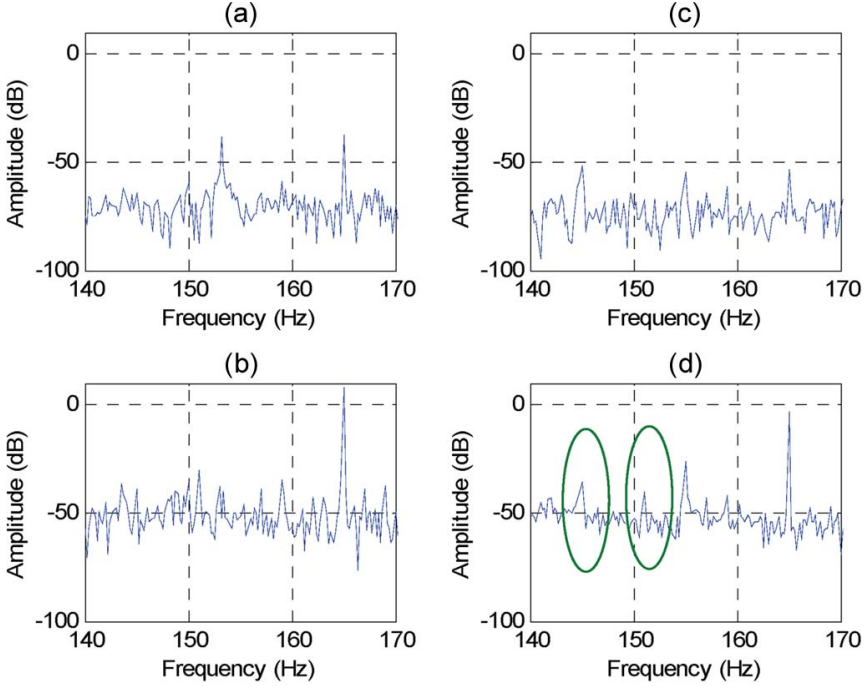

(d)

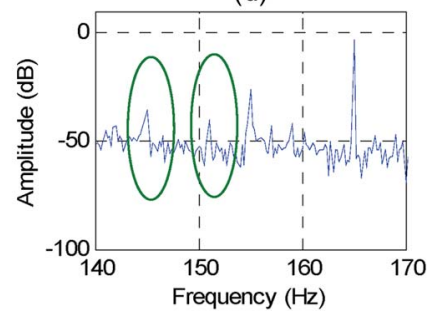

Fig. 11. Stator current spectrum of an IM supplied with $33 \mathrm{~Hz}$. Fifth harmonic sideband. (a) Healthy motor measured with a traditional Rogowski sensor. (b) Healthy motor measured with a Rogowski sensor without an integrator. (c) Motor with broken bars measured with a traditional Rogowski sensor. (d) Motor with broken bars measured with a Rogowski sensor without an integrator.

detected, whereas, with the traditional one, they are so small that they are difficult to differentiate from noise.

Similar results have been obtained with a motor with lower damage level, i.e., with one broken bar, not shown here for the sake of readability.

The proposed Rogowski sensor is also useful for the detection of other faults, such as eccentricity. Fig. 12 illustrates the current spectrum of an IM with an eccentricity fault, supplied with $50 \mathrm{~Hz}$. The harmonics inside an oval are the harmonics that appear due to the fault. The figure depicts how these fault harmonics take more amplitude with the proposed Rogowski sensor. 

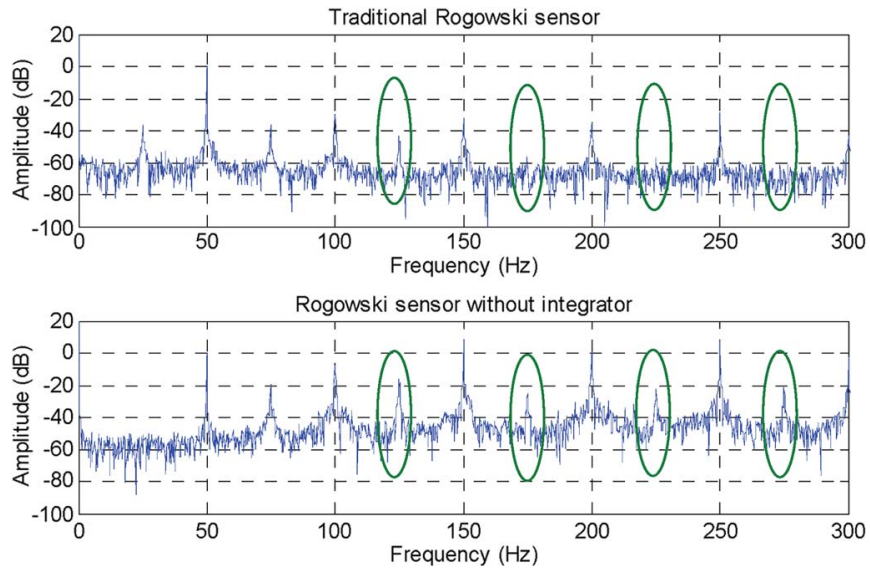

Fig. 12. Stator current spectrum of an IM with eccentricity supplied with $50 \mathrm{~Hz}$. (a) Traditional Rogowski sensor. (b) Rogowski sensor without an integrator.

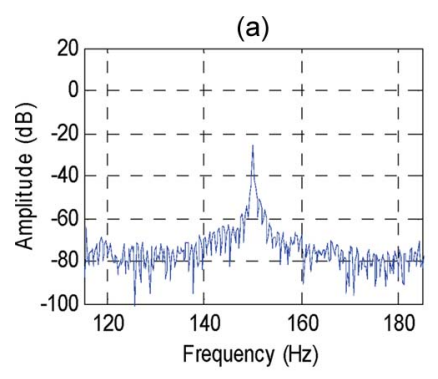

(b)
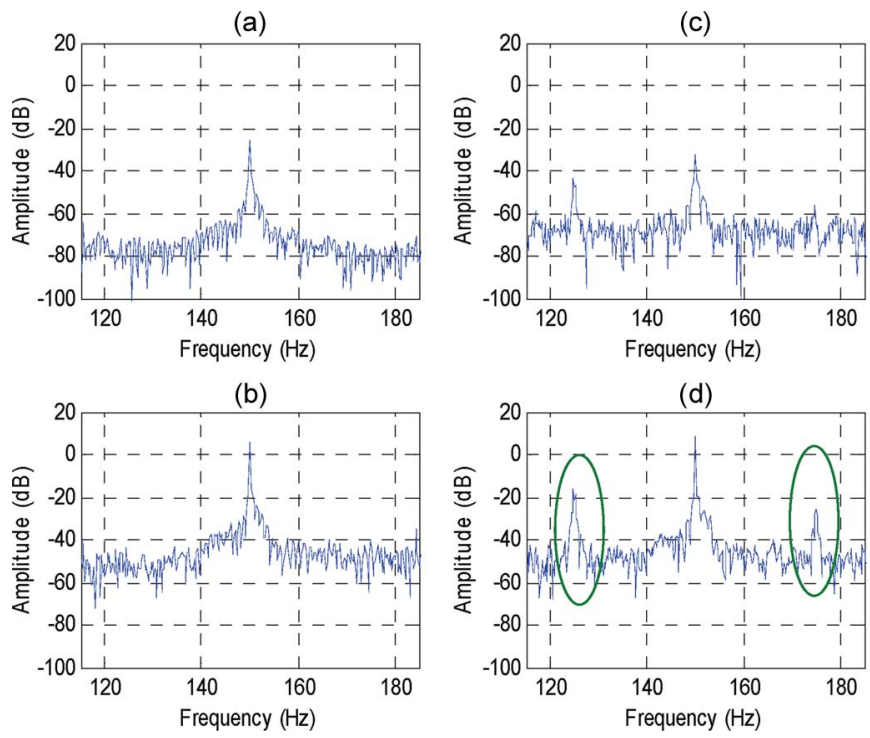

(d)

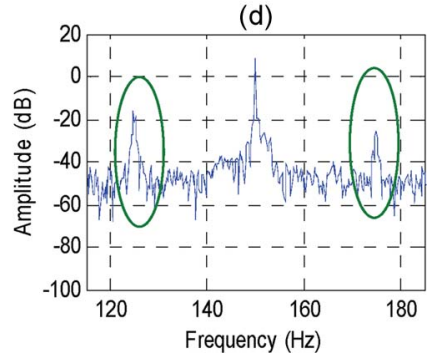

Fig. 13. Stator current spectrum of an IM with eccentricity supplied with $50 \mathrm{~Hz}$. Third harmonic sideband. (a) Healthy motor measured with a traditional Rogowski sensor. (b) Healthy motor measured with a Rogowski sensor without an integrator. (c) Motor with broken bars measured with a traditional Rogowski sensor. (d) Motor with broken bars measured with a Rogowski sensor without an integrator.

Fig. 13 shows the detail near the third harmonic for the motor with an eccentricity fault (right side) as opposed to the healthy motor (left side) supplied with $50 \mathrm{~Hz}$.

The fault harmonics are inside an oval. Fig. 14 depicts the third-harmonic detail for the motor with an eccentricity fault as opposed to the healthy motor for a current supply of $33 \mathrm{~Hz}$. As we can see, the fault harmonics are better detected with nominal speed.

These experimental results allow us to confirm that the Rogowski transducer without the integrator is suitable for MCSA.

The results obtained from the proposed Rogowski sensor have been compared with those obtained with the traditional Rogowski sensor.

With the proposed Rogowski transducer, the harmonics of high frequency take more amplitude than the same harmonics obtained with the other transducers. This effect is not important (a)

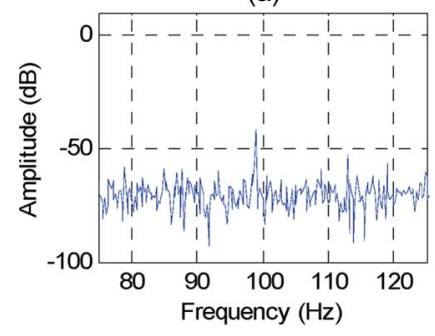

(b)

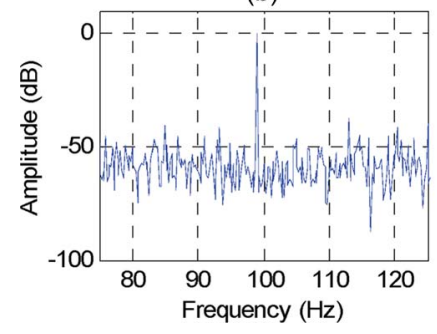

(c)

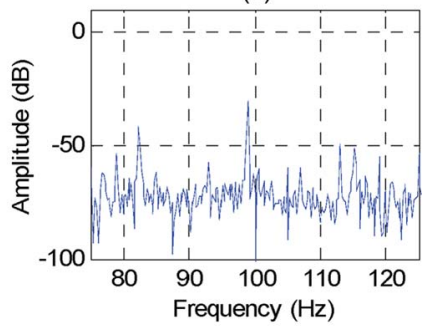

(d)

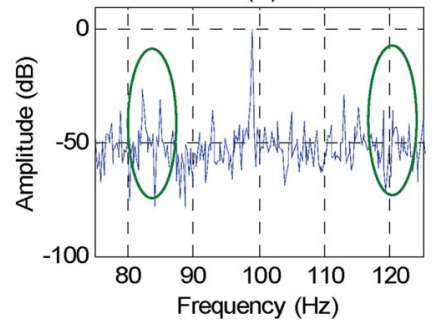

Fig. 14. Stator current spectrum of an IM with eccentricity supplied with $33 \mathrm{~Hz}$. Third harmonic sideband. (a) Healthy motor measured with a traditional Rogowski sensor. (b) Healthy motor measured with a Rogowski sensor without an integrator. (c) Motor with broken bars measured with a traditional Rogowski sensor. (d) Motor with broken bars measured with a Rogowski sensor without an integrator.

at frequencies around $50 \mathrm{~Hz}$, but, at higher frequencies, the amplitude of the harmonics obtained with the Rogowski transducer without an integrator is clearly higher, and it can be used for fault detection at medium-to-high frequencies.

\section{CONCLUSION}

This paper has presented an implementation of a Rogowski coil for fault detection in an IM. To increase the reliability of the acquisition system, it is suggested to remove the integrator that is characteristic in this kind of current probes. In this way, the proposed Rogowski transducer simplifies the electronics; it prevents adjustment problems with integrator circuits, and it performs better at high frequencies. Moreover, the proposed acquisition system has used an adaptive filter to attenuate the fundamental harmonic in order to achieve better use of the dynamic range of the digital acquisition system.

Theoretical analyses and experiments support this paper, and results have shown that this Rogowski transducer without an integrator can be used as an improved sensor for fault detection through stator current readings in electrical motors.

\section{REFERENCES}

[1] M. El Hachemi Benbouzid, "A review of induction motors signature analysis as medium for faults detection," IEEE Trans. Ind. Electron., vol. 47, no. 5, pp. 984-993, Oct. 2000.

[2] S. Nandi, H. A. Toliyat, and L. Xiaodong, "Condition monitoring and fault diagnosis of electrical motors-A review," IEEE Trans. Energy Convers., vol. 20, no. 4, pp. 719-729, Dec. 2005.

[3] A. Bellini, F. Filippetti, C. Tassoni, and G.-A. Capolino, "Advances in diagnostic techniques for induction machines," IEEE Trans. Ind. Electron., vol. 55, no. 12, pp. 4109-4126, Dec. 2008.

[4] L. Zhu, H. Ding, and X. Zhu, "Extraction of periodic signal without external reference by time-domain average scanning," IEEE Trans. Ind. Electron., vol. 55, no. 2, pp. 918-927, Feb. 2008.

[5] D. G. Dorrell, W. T. Thomson, and S. Roach, "Analysis of airgap flux, current, and vibration signals as a function of the combination of static and 
dynamic airgap eccentricity in 3-phase induction motors," IEEE Trans. Ind. Appl., vol. 33, no. 1, pp. 24-34, Jan./Feb. 1997.

[6] A. M. da Silva, R. J. Povinelli, and N. A. O. Demerdash, "Induction machine broken bar and stator short-circuit fault diagnostics based on three-phase stator current envelopes," IEEE Trans. Ind. Electron., vol. 55, no. 3, pp. 1310-1318, Mar. 2008.

[7] M. Drif and A. J. M. Cardoso, "Airgap-eccentricity fault diagnosis, in three-phase induction motors, by the complex apparent power signature analysis," IEEE Trans. Ind. Electron., vol. 55, no. 3, pp. 1404-1410, Mar. 2008.

[8] O. A. Syggeridou and M. G. Ioannides, "Diagnostic methods for ac electric motors. Part 1: Mechanical, chemical and thermal monitoring," in Proc. EPES, 2004, CD-ROM, Track 442-804.

[9] F. Filippetti, G. Franceschini, C. Tassoni, and P. Vas, "Recent developments of induction motor drives fault diagnosis using AI techniques," IEEE Trans. Ind. Electron., vol. 47, no. 5, pp. 994-1004, Oct. 2000.

[10] F. Zidani, D. Diallo, M. H. Benbouzid, and R. Naït-Saït, "A fuzzy-based approach for the diagnosis of fault modes in a voltage-fed PWM inverter induction motor drive," IEEE Trans. Ind. Electron., vol. 55, no. 2, pp. 586593, Feb. 2008.

[11] F. Zidani, M. E. H. Benbouzid, D. Diallo, and M. S. Nait-Said, "Induction motor stator faults diagnosis by a current Concordia pattern-based fuzzy decision system," IEEE Trans. Energy Convers., vol. 18, no. 4, pp. 469475, Dec. 2003

[12] Y. Tan, Y. He, C. Cui, and G. Qiu, "A novel method for analog fault diagnosis based on neural networks and genetic algorithms," IEEE Trans. Instrum. Meas., vol. 57, no. 11, pp. 2631-2639, Nov. 2008

[13] W. W. Tan and H. Huo, "A generic neurofuzzy model-based approach for detecting faults in induction motors," IEEE Trans. Ind. Electron., vol. 52, no. 5, pp. 1420-1427, Oct. 2005.

[14] M. S. Ballal, Z. J. Khan, H. M. Suryawanshi, and R. L. Sonolikar, "Adaptive neural fuzzy inference system for the detection of inter-turn insulation and bearing wear faults in induction motor," IEEE Trans. Ind. Electron., vol. 54, no. 1, pp. 250-258, Feb. 2007.

[15] H. Su and K. T. Chong, "Induction machine condition monitoring using neural network modeling," IEEE Trans. Ind. Electron., vol. 54, no. 1, pp. 241-249, Feb. 2007.

[16] J.-H. Jung, J.-J. Lee, and B.-H. Kwon, "Online diagnosis of induction motors using MCSA," IEEE Trans. Ind. Electron., vol. 53, no. 6, pp. 1842-1852, Dec. 2006.

[17] J. Cusido, L. Romeral, J. A. Ortega, J. A. Rosero, and A. Garcia Espinosa, "Fault detection in induction machines using power spectral density in wavelet decomposition," IEEE Trans. Ind. Electron., vol. 55, no. 2, pp. 633-643, Feb. 2008.

[18] M. Blodt, D. Bonacci, J. Regnier, M. Chabert, and J. Faucher, "On-line monitoring of mechanical faults in variable-speed induction motor drives using the Wigner distribution," IEEE Trans. Ind. Electron., vol. 55, no. 2, pp. 522-533, Feb. 2008.

[19] S. Rajagopalan, J. A. Restrepo, J. M. Aller, T. G. Habetler, and R. G. Harley, "Nonstationary motor fault detection using recent quadratic time-frequency representations," IEEE Trans. Ind. Appl., vol. 44, no. 3, pp. 735-744, May/Jun. 2008.

[20] W. F. Ray and C. R. Hewson, "High performance Rogowski current transducers," in Conf. Rec. IEEE IAS Annu. Meeting, vol. 5, pp. 3083-3090.

[21] Q. Chen, H.-B. Li, M.-M. Zhang, and Y.-B. Liu, "Design and characteristics of two Rogowski coils based on printed circuit board," IEEE Trans. Instrum. Meas., vol. 55, no. 3, pp. 939-943, Jun. 2006.

[22] E. Abdi-Jalebi and R. McMahon, "High-performance low-cost Rogowski transducers and accompanying circuitry," IEEE Trans. Instrum. Meas., vol. 56, no. 3, pp. 753-759, Jun. 2007.

[23] R. Ong, J. H. Dymond, and R. D. Findlay, "Bearing damage analysis in a large oil-ring-lubricated induction machine," IEEE Trans. Ind. Electron., vol. 47, no. 5, pp. 1085-1091, Oct. 2000.

[24] J. D. Bull, N. A. F. Jaeger, and F. Rahmatian, "A new hybrid current sensor for high-voltage applications," IEEE Trans. Power Del., vol. 20, no. 1, pp. 32-38, Jan. 2005

[25] M. Rigoni, J. S. D. Garcia, A. P. Garcia, P. A. Da Silva, N. J. Batistela, and P. Kuo-Peng, "Rogowski coil current meters," IEEE Potentials, vol. 27, no. 4, pp. 40-45, Jul./Aug. 2008.

[26] A. Radun, "An alternative low-cost current-sensing scheme for highcurrent power electronics circuits," IEEE Trans. Ind. Electron., vol. 42, no. 1, pp. 78-84, Feb. 1995.

[27] O. Poncelas, J. A. Rosero, J. Cusido, J. A. Ortega, and L. Romeral, "Design and application of Rogowski coil current sensor without integrator for fault detection in induction motors," in Proc. IEEE Int. Symp. Ind. Electron., Jun./Jul. 2008, pp. 558-563.
[28] J. Cusido, J. A. Rosero, J. A. Ortega, A. Garcia, and L. Romeral, "Induction motor fault detection by using wavelet decomposition on dq0 components," in Proc. IEEE Int. Symp. Ind. Electron., vol. 3, pp. 2406-2411.

[29] F. Briz, M. W. Degner, P. Garcia, and A. B. Diez, "High-frequency carriersignal voltage selection for stator winding fault diagnosis in inverter-fed ac machines," IEEE Trans. Ind. Electron., vol. 55, no. 12, pp. 4181-4190, Dec. 2008.

[30] C. Demian, A. Mpanda-Mabwe, H. Henao, and G. A. Capolino, "Detection of induction machines rotor faults at standstill using signals injection," IEEE Trans. Ind. Appl., vol. 40, no. 6, pp. 1550-1559, Nov./Dec. 2004.

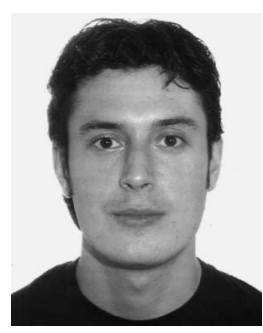

Oscar Poncelas was born in Barcelona, Spain, in 1978. He received the B.S. and M.S. degrees in electronic engineering from the Universitat Politècnica de Catalunya (UPC), Barcelona, Spain, in 2001 and 2008, respectively.

Since 2002, he has been with the Department of Electronic Engineering, UPC, as a Technical Staff, where he is currently with the Motion Control and Industrial Applications Group, where the group's major research activities concern induction and permanent magnet motor drives, enhanced efficiency drives, and fault detection and diagnosis of electrical motor drives.

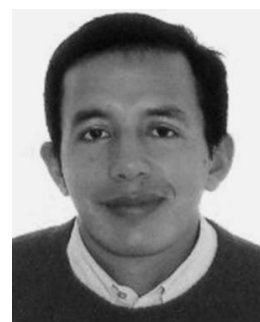

Javier A. Rosero was born in Potosi, Colombia, in 1978. He received the B.S. degree in electrical engineering from the Universidad of Valle, Cali, Colombia, in 2002, and the Ph.D. degree from the Universitat Politècnica de Catalunya (UPC), Barcelona, Spain, in 2007.

Between 2002 and 2004, he worked in the maintenance of power systems and substations in Bogotá, Colombia. He is currently a Senior Engineer with the ABB Company, Spain, where he is working in the field of motor control and applications. He actively collaborates with the Motion Control and Industrial Applications Group (MCIA) as researcher. His research interests are focused on the areas of simulation, modeling, supervision, diagnosis, and control of electrical machines and drives.

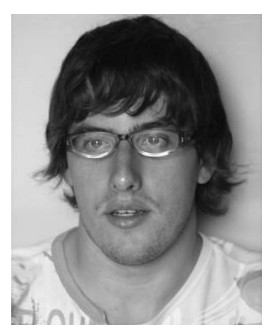

Jordi Cusidó (M’09) was born in Sabadell, Spain, in 1979. He received the B.S. degree in electrical engineering from the Universitat Politècnica de Catalunya (UPC), Barcelona, Spain, in 2005.

In 2005, he joined the Department of Electronic Engineering, UPC, where he is currently with the Motion Control and Industrial Applications Group as an Assistant Professor teaching courses on analog electronics for aeronautical applications. The group's major research activities concern induction and permanent magnet motor drives, enhanced efficiency drives, direct torque controllers, and sensorless vector drives. The group is also active in motor fault detection algorithms, automotive drive applications, data acquisition systems, and signal processing and adaptive control. His research interests include electrical machines, variable speed drive systems, electrical systems for automotive and aeronautical applications, and fault detection algorithms. He has authored more than ten peer-reviewed scientific papers published in technical journals and conference proceedings. He participates in EuropeanUnion- and Spanish-government-funded projects. He has also participated as an Engineer or responsible for research and development projects funded by local private companies, in the areas of electrical machine design and industrial control. He collaborates with automotive companies for the distribution of their components and subsystems.

Mr. Cusidó is a member of the IEEE Industrial Electronics Society and IEEE Aerospace and Electronic Systems Society. He is also a member of the Technological Centre of Manresa (CTM), where he is responsible for technological assistance to several industries and university departments in the fields of automotive and aeronautical applications. 


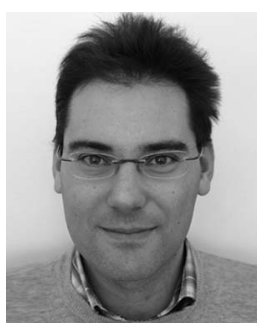

Juan Antonio Ortega (M'94) received the M.S. degree in telecommunication engineering and the Ph.D. degree in electronics from the Universitat Politècnica de Catalunya (UPC), Barcelona, Spain, in 1994 and 1997, respectively.

In 1994, he joined the Department of Electronic Engineering, UPC, as a full-time Associate Lecturer, where, since 2001, he has been with the Motion Control and Industrial Applications Group, where the group worked in the area of motor current signature analysis. From 1994 to 2001, he was with the Sensor Systems Group, where he worked in the areas of smart sensors, embedded systems, and signal conditioning, acquisition, and processing. Since 1994, he has taught courses on microprocessors and signal processing. In 1998, he obtained a tenured position as an Associate Professor. His current R\&D areas include motor diagnosis, signal acquisition, smart sensors, embedded systems, and remote labs. In the last several years, he has participated in several Spanishand European-funded research projects about these items. He has more than 30 referred journal and conference papers.

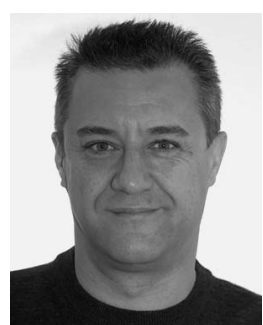

Luis Romeral (M'98) received the B.S. degree in electrical engineering and the Ph.D. degree from the Universitat Politècnica de Catalunya (UPC), Barcelona, Spain, in 1985 and 1995, respectively.

$\mathrm{He}$ is currently with the Motion Control and Industrial Applications Group, Department of Electronic Engineering, UPC. The group's major research activities concern induction and permanent magnet motor drives, fault detection and diagnosis of electrical motor drives, and energy efficiency. His research interests include electric machines, power electronics converters and modulation strategies, variable speed drive systems, fault detection and motor diagnosis, and microprocessor-based real-time control algorithms. He has developed and taught postgraduate courses on programmable logic controllers, electrical drives and motion control, and sensors and actuators. He has authored more than 50 peer-reviewed scientific papers, and seven $\mathrm{Ph} . \mathrm{D}$. dissertations have been completed under his supervision over the last years. He participates as a Partner or Subcontractor in European-Union-funded projects, and, additionally, he is responsible for several research projects funded by Spanish agencies. He has also participated as an Engineer or responsible for research and development projects funded by local private companies.

Dr. Romeral is a member of the IEEE Industrial Electronics Society and the European Power Electronics and Drives Association as well as the International Federation of Automatic Control. 